\title{
Effectiveness, relapse prevention and mechanisms of change of cognitive therapy vs. interpersonal therapy for depression: Study protocol for a randomised controlled trial
}

\author{
Lotte HJM Lemmens ${ }^{1 *}$, Arnoud Arntz ${ }^{1}$, Frenk PML Peeters ${ }^{2}$, Steven D Hollon ${ }^{3}$, Anne Roefs ${ }^{1}$ and
} Marcus JH Huibers ${ }^{1}$

\begin{abstract}
Background: Major depression is a common mental disorder that substantially impairs quality of life and has high societal costs. Although psychotherapies have proven to be effective antidepressant treatments, initial response rates are insufficient and the risk of relapse and recurrence is high. Improvement of treatments is badly needed. Studying the mechanisms of change in treatment might be a good investment for improving everyday mental health care. However, the mechanisms underlying therapeutic change remain largely unknown. The objective of the current study is to assess both the effectiveness of two commonly used psychotherapies for depression in terms of reduction of symptoms and prevention of relapse on short and long term, as well as identifying underlying mechanisms of change.
\end{abstract}

Methods: In a randomised trial we will compare (a) Cognitive Therapy (CT) with (b) Interpersonal therapy (IPT), and (c) an 8-week waiting list condition followed by treatment of choice. One hundred eighty depressed patients (aged 18-65) will be recruited in a mental health care centre in Maastricht (the Netherlands). Eligible patients will be randomly allocated to one of the three intervention groups. The primary outcome measure of the clinical evaluation is depression severity measured by the Beck Depression Intenvory-II (BDI-II). Other outcomes include process variables such as dysfunctional beliefs, negative attributions, and interpersonal problems. All self-report outcome assessments will take place on the internet at baseline, three, seven, eight, nine, ten, eleven, twelve and twenty-four months. At 24 months a retrospective telephone interview will be administered. Furthermore, a rudimentary analysis of the cost-effectiveness will be embedded. The study has been ethically approved and registered.

Discussion: By comparing CT and IPT head-to-head and by investigating multiple potential mediators and outcomes at multiple time points during and after therapy, we hope to provide new insights in the effectiveness and mechanisms of change of CT and IPT for depression, and contribute to the improvement of mental health care for adults suffering from depression.

Trial registration: The study has been registered at the Netherlands Trial Register, part of the Dutch Cochrane Centre (ISRCTN67561918)

\footnotetext{
* Correspondence: lotte.lemmens@maastrichtuniversity.nl 'Department of Clinical Psychological Science, Faculty of Psychology and Neuroscience, Maastricht University, the Netherlands

Full list of author information is available at the end of the article
} 


\section{Background}

With a lifetime prevalence of $17 \%$, depression is a major health problem with serious clinical and social consequences. It is expected that depression will be the leading global cause of years of health lost due to disease in 2030 [1]. With initial response rates up to $60 \%$, and the majority of patients regaining their normal level of functioning within three years, certain psychotherapies and antidepressant medication have proven efficacy in treating acute Major Depressive Disorder (MDD) [2,3]. This might sound promising, but at least $40 \%$ of depressed patients do not respond to initial treatment at all. Furthermore, depression has an unfavourable prognosis; even when treated effectively in the acute phase, recovery is often incomplete, which increases the chance of relapse and recurrence up to $87 \%$ over 15 years [4-7].

With this in mind, the challenge in contemporary depression research is to improve treatments to increase acute response rates and prevent relapse and recurrence in the long term. Many researchers agree that knowledge of underlying mechanisms that can explain therapeutic change is a key to improving treatment $[8,9]$. Knowing how a therapy works would allow honing its components to make it more efficient and (cost-)effective [10]. The current study will focus on the effectiveness, prevention of relapse and recurrence and mechanisms of change of two commonly used types of psychotherapy for depression: Cognitive Therapy (CT) [11] and Interpersonal Therapy (IPT) [12]. A rudimentary analysis of the cost-effectiveness from a societal perspective will be embedded.

\section{Effectiveness}

Of the psychotherapeutic interventions for depression, $\mathrm{CT}$ and IPT might be the two best studied and empirically validated [13-15]. They come from different theoretical backgrounds: CT derives from Beck's cognitive theory and explains depression as a result of maladaptive information-processing, whereas IPT links depressive episodes to distressing life events and insufficient social support $[12,16]$. Nonetheless, both therapies have proven to be well-standardized, efficacious treatments for acute treatment of MDD [3,12,17-23]. There is no consensus yet about whether the effect of one therapy outperforms the other. Many studies have investigated the effects of CT and IPT separately, but only 2 large studies have compared them head-to-head [24-26]. However, doubts have arisen about the validity of one of these studies because analysis of treatment adherence showed no contrast between the two intervention groups [24,27]. Thus, the current view is based on only one methodologically well-designed study. Therefore, there is a need for renewed head-to-head comparisons of both therapies.

\section{Relapse Prevention}

In addition to the fact that CT and IPT have shown to be efficacious acute treatments of MDD, they may also reduce the risk of relapse (episode of MDD after remission) and recurrence (episode of MDD after recovery) in the long term. The effects and evidence differ for the two therapies. Research has shown that CT has an enduring effect that extends beyond the end of therapy [12,28-33], thereby reducing the chances of relapse and recurrence. The evidence for this is strong and consistent $[31,34,35]$. However, the long term effect of IPT has not been tested extensively yet. Up until now it has only been tested as a maintenance treatment $[36,37]$, and the question remains whether IPT also has an enduring effect that remains after therapy is finished. This question should be further explored. Insight in the long term effects of IPT furthermore creates the opportunity to compare CT and IPT to assess whether one therapy is superior to the other in preventing relapse and recurrence in the long term [15].

\section{Mechanisms of Change}

As noted above, insight into mechanisms of change might contribute to the process of therapy improvement. However, the mechanisms that cause therapeutic change are still largely unknown. Despite several research attempts to identify the mechanisms of change in psychotherapy, no study has identified a model that explains change in CT or IPT completely $[38,39]$. Mechanism research has to cope with several methodological and theoretical difficulties $[40,41]$. Theoretical difficulties arise because there are conflicting hypotheses on the mechanisms and there is no consensus about the most important causes of change [38,42]. For example, it is unclear whether therapeutic change can be better explained by change in treatment specific factors [42-45] or non-specific (common) factors [46-48]. Specific factors are elements marked as the active causes of change in the theory of the therapy, such as change in cognitions in CT and optimization of interpersonal functioning in IPT. Non-specific factors refer to elements in a therapy that contribute to improvement, but that are common to all psychotherapies, such as expectancy and therapeutic alliance [49]. Furthermore, it is not exactly known whether changes achieved in therapy are best reflected by explicit or by implicit measures of psychopathology. Explicit measures depend on introspection, and a disadvantage is that it is known that people do not have access to all of the mechanisms that underlie their behaviour [50]. An implicit measure is defined by De Houwer, Teige-Mocigemba, Spruyt, and Moors (2009) as "a measurement outcome that is causally produced by the to-be-measured attribute in the absence of certain goals, awareness, 
substantial cognitive resources, or substantial time" (p. 350) [51]. To the extent that implicit measures reflect uncontrollable, unaware, fast mechanisms, they could provide information that augments that from explicit measures [52].

Furthermore, methodological difficulties arise because many study designs do not meet the criteria for reputable mechanisms research $[40,41]$. Theories often explain change in terms of causal processes. However, in many studies it is difficult to identify temporal relationships in order to investigate these causal pathways because of the absence of an appropriate time line and assessment on multiple time points $[40,41]$. It is clear that there is a need for renewed, methodologically well-considered mechanism research.

The question remains what is necessary for proper mechanism research. According to Kazdin (2007), a first step into investigating mechanisms of change is studying mediating variables [40]. A mediator explains why and in what way a treatment has an effect on the outcome, and plays a crucial role in the development of causal pathways. In identifying mediators, Kazdin has built upon the MacArthur guidelines of Kraemer et al. (2001) [53] which are based on the more traditional guidelines for statistical mediation formulated by Baron and Kenny (1986) [54]. In addition to statistical mediation and association, Kazdin emphasizes the importance of the temporal relationship, and consistency and specificity of the mediator. The importance of the aspect of temporality is also emphasized by Murphy et al (2009) [55]. Taking this into account, the current study will investigate potential mediators of CT for depression and test their specificity in comparison to IPT, and vice versa, by measuring multiple potential mediators and outcomes at multiple time points during and after therapy. This method enables us to investigate temporal relationships between changes in potential mediators and symptom reduction and to assess whether change in a mediator precedes, follows from, or goes together with changes in depression. In addition, this method can show us whether change in one mediator precedes change in another mediator.

\section{Main research questions and Hypotheses}

The following main research questions were formulated:

- Are CT and IPT effective interventions in treating the acute phase of MDD and is one therapy superior to the other?

- What are the underlying psychological mechanisms of change in CT and IPT and are these mechanisms therapy-specific?

- Are CT and IPT effective in preventing relapse or recurrence of MDD in the long-term? Is one therapy superior to the other, and if so, how can these preventive effects be explained?

In line with previous research, it is hypothesized that the amount of change in depressive symptoms after therapy will be similar in both the CT and the IPT group, indicating that both treatments are just as effective in treating depression in the acute phase $[14,24,56,57]$. Because both therapies originally stem from different theoretical backgrounds, we expect that both treatments target depression through different key processes. It is expected that changes in cognitive schemas, attitudes, and cognitions are the most significant contributors to symptom change in $\mathrm{CT}$, whereas in IPT it is assumed that improvement of interpersonal functioning will lead to a reduction of symptoms $[12,16]$. With regard to the mechanisms of change, many hypotheses are possible, especially when it comes to the order of change and causal pathways that lead to recovery. Following the theories one would expect that change in cognitions (CT) and interpersonal functioning (IPT) precede symptom change. Furthermore, we expect that it is the direct comparison of explicit versus implicit measures that will elicit new insights into the underlying mechanisms of change. To the extent that implicit measures reflect uncontrollable, unaware and fast mechanisms, they can provide useful additional information as compared to explicit measures. As to the prevention of relapse, we hypothesize that both $\mathrm{CT}$ and IPT may reduce the risk of relapse and recurrence in the long term. However, we expect CT to prevent relapse to a greater extent, because it has shown to have an enduring effect that extends beyond the end of therapy, while IPT so far only seems to be effective in treating depression as long as the treatment is continued [58].

\section{Methods}

\section{Design of the study}

We will conduct a randomised controlled trial (RCT) in which participants will be allocated to one of three conditions: (a) CT $(N=75)$, (b) IPT $(N=75)$, (c) or a waiting list condition followed by treatment of choice $(N=$ 30). Participants allocated to the waiting list condition start their treatment after an 8-week waiting period. To compensate for the waiting, they may choose their preferred treatment (CT or IPT). The anticipated flow of subject enrolment is graphically shown in Figure 1. The Medical Ethics Committee of Maastricht University approved the study protocol. The study is registered at the Netherlands Trial Register, part of the Dutch Cochrane Centre (ISRCTN67561918).

\section{Participants}

The population we aim to investigate consists of 180 depressed adults. Patients will be eligible to participate if 


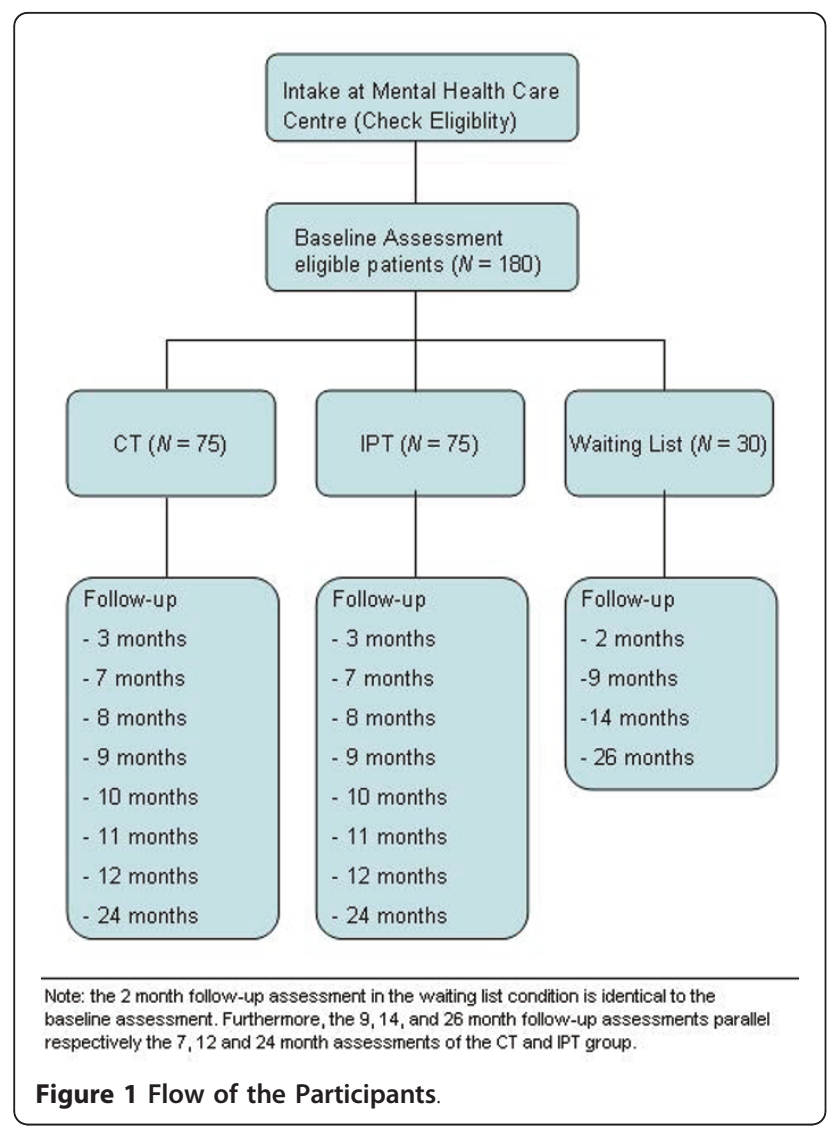

they meet the following criteria: age between $18-65$ years old; the presence of a depressive episode as indicated by a diagnosis on the Structural Clinical Interview for DSM-IV Axis I disorders (SCID-I) [59]; internet access and an e-mail address; sufficient knowledge of the Dutch language; no chronic depression ( $>5$ years); no current use of antidepressant mediation; no severe psychiatric co-morbidity, drugs- and alcohol abuse/ dependence and oligophrenia.

\section{Sample size}

To calculate the sample size of the CT and IPT group, we combined rudimentary findings from previous randomised trials, which resulted in a mean relapse/recurrence rate of $33 \%$ after two years of follow-up, compared to $67 \%$ following antidepressant medication and/or clinical management [28,29,31-33]. Based on these results, we assume a difference of $20 \%$ in relapse between CT and IPT. Using survival analysis (two-sided, $\alpha=0.05$, power $=80 \%$ ), we calculated that 75 patients per treatment condition would suffice to detect this statistically significant difference rate in relapse/recurrence between the two conditions in the long term.

A waiting list condition is included to investigate whether the effects of CT and IPT exceed the outcome in patients who do not receive treatment, a finding that has been demonstrated in numerous previous studies [60-63]. A power calculation showed that 30 participants in the waiting list condition will be sufficient to detect a statistically significant difference between the two active conditions combined (CT and IPT) and the waiting list after eight weeks.

\section{Recruitment}

Participants will be recruited during regular intakes at our clinical site, the Academic Community Mental Health Centre (RIAGG) Maastricht. The SCID-I will be administered to assess current and lifetime episodes of Axis I disorders [59]. Patients meeting the inclusion criteria will be approached for participation. If they agree to participate, the SCID for Axis II disorders (SCID-II) will be administered as well [64]. After inclusion, the participants' GP will be informed about his or her participation in the study. Participants who do not meet the inclusion criteria will be offered suitable alternative treatment options.

\section{Randomisation and procedure}

Eligible participants will be contacted by telephone for a baseline visit at the university. Preceding this initial visit to the research centre, participants will receive an appointment letter, including study information. This will allow them to consider their study participation well before they agree to participate (approximately one week). Furthermore, to decrease the burden of the first assessment, participants will be asked to already fill out a substantial part of the baseline questionnaires at home. Randomisation will take place after informed consent is obtained and the second part of the baseline questionnaires are filled out. In our design we prestratified groups by first ( 1 episode) and recurrent (> 1 episodes) depression. The researcher will press the 'assign' button on the computer screen, after which the database randomly allocates the participant to one of the treatment conditions (CT or IPT), or to the waiting list condition by using block randomisation. This waiting list condition is included because it has been frequently argued in psychotherapy research that the effect in treatment studies cannot be attributed to the intervention(s) that are studied, unless a placebo or no-treatment group is included [65]. With regard to the nature of the treatments, blinding of the participants and researchers is not possible.

In reporting the follow-up period of the CT and IPT condition in this study, we distinguish three phases; (a) the Treatment phase (baseline to 7 months); the period when therapy will be delivered; (b) The Trial follow-up phase (month 8-12) in which depression severity will be measured monthly; and (c) The Long-term follow-up 
phase (12 to 24 months); the period covered by retrospective assessment. All questionnaires will be administered on a computer. Pre- and post treatment assessment (baseline and 7 months) will take place at the University. All other follow-up self-report assessments will take place at home via the internet at three, eight, nine, ten, eleven, twelve and twenty-four months after inclusion.

Although the baseline assessment is the same, the follow-up period of the waiting list condition is somewhat different as compared to the CT and IPT condition (see Figure 1). Participants in this condition will be measured less often, and at different points in time. The treatment phase of the participants in this condition does not start immediately after baseline, but after an 8-week waiting list period. To be able to investigate the effect of this waiting period, and to mark the starting point of the treatment phase, a second identical baseline assessment will take place two months after the initial baseline assessment. As a consequence, the post-treatment assessment in this condition will take place after nine months (instead of after seven months in the CT and IPT condition). Furthermore, patients in this condition will only have two more assessment after their posttreatment measure. This will take place at 14 and 26 months, and is identical to the 12 and 24 months assessment of the CT and IPT condition. To summarize, patients in the waiting list condition will have the same baseline assessment as compared to participants in the CT and IPT condition. However, they will have a second baseline assessment at two months follow-up, and their 9,14 , and 26 month follow-up assessments will parallel respectively the 7,12 , and 24 months assessments of the $\mathrm{CT}$ and IPT group (see table 1).

In all conditions a BDI-II will be filled out before each session during the treatment phase. After the two-year follow-up period, a modified version of the semi-structured Longitudinal Interval Follow-Up Evaluation (LIFE) [66] will be administered to retrospectively map out the course of depressive symptoms. To optimize the adherence of self-report assessments, participants will receive an email foregoing each assessment point. If one does not complete the questionnaires within one week, an email-reminder will be sent. If the participant still fails to fill out the questionnaires, a phone call will be made.

\section{Interventions}

The interventions will be offered at the Academic RIAGG Maastricht. At this site, CT and IPT are already delivered as treatment as usual. Interventions are written out in a treatment manual, and both treatments will contain 12 to 20 sessions of 45 minutes, depending on the individual progress of patients. Interventions will be delivered by qualified therapists, who were trained by Steven Hollon (CT) and John Markowitz (IPT), experts
Table 1 Overview of instruments per time point in the CT and IPT group*

\begin{tabular}{|c|c|c|c|c|c|c|}
\hline Instrument & $0 * *$ & 3 & 7 & 8-11 & 12 & 24 \\
\hline \multicolumn{7}{|l|}{ Clinical Outcome measures } \\
\hline Beck Depression Inventory II & • & $\cdot$ & • & • & • & $\cdot$ \\
\hline $\begin{array}{l}\text { Quick Inventory of Depressive } \\
\text { symptoms }\end{array}$ & $\cdot$ & & & & • & \\
\hline Brief Symptom Inventory & • & & - & & • & - \\
\hline Diagnostic Interview for Depression & & • & - & • & • & - \\
\hline Beck Hopelessness Scale & - & & • & & & \\
\hline $\begin{array}{l}\text { Longitudinal Interval Follow-up } \\
\text { Evaluation }\end{array}$ & & & & & & - \\
\hline \multicolumn{7}{|l|}{ Process variables } \\
\hline Attributional Style questionnaire & $\cdot$ & $\cdot$ & • & & • & \\
\hline Dysfunctional Attitude Scale & $\cdot$ & • & • & & • & \\
\hline Inventory of Interpersonal Problems & $\cdot$ & • & • & & • & - \\
\hline Leiden Index of Depression Severity & • & • & - & & & \\
\hline Ruminative Response Scale NL & $\cdot$ & $\cdot$ & • & & & \\
\hline $\begin{array}{l}\text { Self-Liking and Self-Competence } \\
\text { Scale }\end{array}$ & • & • & • & & & \\
\hline $\begin{array}{l}\text { Single Category Implicit Association } \\
\text { Task }\end{array}$ & - & & • & & & \\
\hline \multicolumn{7}{|l|}{ Economic Evaluation measures } \\
\hline Health care use Questionnaire & • & $\cdot$ & - & & • & - \\
\hline $\begin{array}{l}\text { Productivity and Disease } \\
\text { Questionnaire }\end{array}$ & - & & • & & • & - \\
\hline Work and Social Adjustment Scale & • & & - & & • & - \\
\hline Euroqol-6D & • & & • & & • & - \\
\hline Rand 36 & $\cdot$ & & • & & • & $\cdot$ \\
\hline Other measures & - & & & & & \\
\hline \multicolumn{7}{|l|}{ Genetic information } \\
\hline Working Alliance Inventory & & $\cdot$ & & & & \\
\hline $\begin{array}{l}\text { Collaborative Study Psychotherapy } \\
\text { Rating Scale }\end{array}$ & • & $\cdot$ & .*** & & & \\
\hline $\begin{array}{l}\text { Working Alliance Inventory-short } \\
\text { observer version }\end{array}$ & • & • & $\bullet * * *$ & & & \\
\hline
\end{tabular}

* Patients in the waiting list condition will receive the same baseline assessment, they will have a second baseline assessment at 2 months followup, and their 9, 14, and 26 month follow-up assessments parallel respectively the 7, 12, and 24 month assessments of the CT and IPT group. ** The following general predictors will be administered at baseline as well: demographic variables, family anamnesis, childhood experiences, life-events, reliability and expectations. *** During the treatment phase, all sessions will be videotaped. Only a random selection of tapes will be rated.

in the field of depression treatment. To prevent contamination of treatment conditions, participating therapists will deliver either CT or IPT. Therapists will consult each other on current cases in biweekly consultation meetings. The CT protocol is based on the manual by Beck (1979) and is modified for the current study with a special focus on relapse prevention. IPT is based on the manual of Klerman, Weissman, Rounsaville, and Chevron 
(1984). CT and IPT differ in terms of target (cognitions and behaviour vs. interpersonal functioning), approach (directive vs. empathic-reflective) and method (homework assignment vs. no assignments) [27]. All sessions will be videotaped, and a random selection of tapes will be analysed by independent assessors on treatment adherence (content and quality) by using the Collaborative Study Psychotherapy Rating Scale - version 6 (CSPRS-6) [67], and on quality of therapeutic alliance using the Observer version of the Working Alliance Inventory-Short (WAI-O-S) [68-72].

\section{Instruments}

Several instruments will be used to assess the effects of CT and IPT on depressive symptoms and other secondary outcomes. Furthermore, instruments will be used to assess the mechanisms of change and the cost-effectiveness of CT and IPT. An overview of all measurements per assessment is given in table 1 .

\section{Clinical outcome measures}

\section{Beck Depression Inventory-II}

The Beck Depression Inventory-II (BDI-II) [73,74] will be used as the primary outcome measure of depressive severity. The total score is the sum of the 21 items ranging from 0 to 63 . Higher scores reflect more severe depressive symptoms. Several studies have shown that the BDI-II is a strong screening measure for depression [73-75].

\section{Quick Inventory of Depressive Symptoms}

The Quick Inventory of Depressive Symptoms (QIDS) [76] is a treatment sensitive measure of symptom severity in depression. The 16 items that measure 9 criterion domains of MDD are derived from the 30-item Inventory of Depressive Symptomatology (IDS) [77]. The QIDS has been shown to have highly acceptable psychometric properties [78].

\section{Brief Symptom Inventory}

The Brief Symptom Inventory (BSI) [79] is a 53-item self-report instrument that will be used to measure general psychological distress. It is derived from the SCL90-R and several studies have demonstrated it to be an acceptable short alternative of its longer version $[80,81]$.

\section{Diagnostic Inventory for Depression}

The Diagnostic Inventory for Depression (DID) will be used to assess the psychosocial impairment due to depression, and to evaluate subjective quality of life $[82,83]$. Psychometric analysis shows good reliability and validity [82].

\section{Longitudinal Interval Follow-up Evaluation}

The modified version of the semi-structured Longitudinal Interval Follow-up Evaluation (LIFE) [66] will be used to map out the course of depressive symptoms in the long-term follow-up phase (12-24 months). This will be administered at the end of the follow-up (24 months). We used the MDD section of the original interview, and added items on general functioning, working status, relations to others and treatment- and study experiences. The LIFE has shown to be a reliable and valid instrument for characterizing the course of several mental disorders examined retrospectively over the period of one year $[84,85]$.

\section{Process (or mechanism) variables Dysfunctional Attitudes}

The Dysfunctional Attitude scale version a (DAS-A) [86-88] is a self-report scale designed to measure patterns of negative and absolute thinking in depressed patients. Respondents need to report whether or not they agree with a series of dysfunctional assumptions on a seven point Likert-Scale. With its good internal consistency and validity, it appears to be a valid measure of dysfunctional cognitions in depressed patients [89-92].

\section{Attributional Style}

Attributional style will be measured using the Attributional Style Questionnaire (ASQ) [93,94]. In the ASQ, participants receive 12 hypothetical events and are asked to imagine themselves in that scenario. Subsequently they have to decide what the major cause of the situation would be if it happened to themselves and rate the cause along a 7-point Likert-scale on three dimensions: Personal, Permanent and Pervasive. Depressive symptoms are associated with an attributional style in which the causes of good and bad events are attributed to internal (versus external), stable (versus unstable), and global (versus specific) causes [95]. It is hypothesized that if attributional style changes significantly during therapy, the explanations of why events happen change to external, unstable and specific. The ASQ has shown to have good psychometric properties [93].

\section{Implicit measure of self-esteem}

A variant of the Single Category Implicit Association Test (Sc-IAT) [96] will be administered to obtain an implicit measure of associations with the self (selfesteem). For the current study, we adapted the original Sc-IAT paradigm to specifically measure feelings of helplessness, unlovability and worthlessness, which are considered the main themes of core beliefs in depression. The test consists of 3 blocks of trials and starts with a practice block. In this block, positive and negative words are presented (all words are related to the specific core beliefs), and the task for participants is to categorize these stimuli as such by pressing the appropriate key (left or right) without making too many errors. After the practice block, there are two test blocks. In one critical block, stimuli representing the self ('me-trials') share a response key with positive stimuli, while the other key needs to be pressed for negative stimuli. In the other 
critical block, the target key assignment for me-trials is switched. Stimuli representing the self now share a response key with the negative stimuli. Each block is preceded by a set of instructions concerning the dimension(s) of the categorisation task and the appropriate key response. The rationale behind the Sc-IAT is that the response time will be faster when two associated concepts are mapped together on the same key, compared to when two less compatible concepts are mapped together. For example, in people with a positive sense of self-esteem, when 'valuable' and 'me' meaning words are mapped to the same key, the response time will be faster than for the non-compatible combination ('worthless' and 'me'). The Sc-IAT effect will be calculated using the improved D-Algorithm [97]. In comparison with implicit measures obtained via other measurement procedures, the Sc-IAT shows good psychometric qualities [98-101].

\section{Hopelessness}

The Beck Hopelessness Scale (BHS) [102] is a self-report instrument that determines the extent of positive and negative beliefs about the future over the previous 7 days using 20 true-false statements. All statements are scored 0 or 1 with the total being calculated by summing the pessimistic responses for the items. General cut-off guidelines do not exist and it is recommended that cut-off scores should be based upon clinical decisions. The BHS has been shown to have good psychometric properties for application in clinical samples [103-105].

\section{Interpersonal Problems}

The Inventory of Interpersonal Problems (IIP) [106] is a 127-item self-report measure, which describes the types of problems that people experience in their relationships with others, and the level of distress associated with them. Items are divided in two sections: participants are asked to rate problematic behaviour that is hard for them to do (78 items) and behaviour that they are doing too much (49 items). The IIP provides a total score and scores on six or eight subscales. Higher scores indicate more interpersonal problems. Psychometric properties of the IIP were found to be good [106].

\section{Cognitive Reactivity}

During a depressive episode, an association is formed between depressed mood and dysfunctional thinking. This association may remain intact even when the depressive episode remits. The strength of this association is called cognitive reactivity [107]. The Leiden Index of Depression Sensitivity (LEIDS) is used to measure this cognitive reactivity on six subscales [108]. Psychometric qualities of this measurement are found to be good [108].

\section{Rumination}

The Ruminative Response Scale (RRS) [109,110] is a 22item questionnaire that will be used to detect the responses to depressed mood that are focused on self, symptoms, or possible consequences and causes of mood. People are asked to indicate how often they think about certain things on a four point Likert-scale. The RRS shows good reliability and satisfactory validity $[109,110]$.

\section{Self-Esteem}

The Self Liking and Self Competence Scale Revised (SLCS-R) $[111,112]$ is a self-report questionnaire constructed to measure Self-Competence and Self-Liking, two dimensions of self-esteem. The SLSC-R contains eight items for each of the two dimensions. Items are rated on a 5-point Likert scale. The subscales scores can range from 8 to 40, with higher scores indicating higher self-competence or higher self-liking. Psychometric properties were found to be good [111].

\section{Economic Evaluation \\ Costs}

A rudimentary analysis of the cost-effectiveness of CT and IPT will be conducted from a societal perspective. We will distinguish three cost categories: health care sector costs, costs for the patient and family, and productivity cost [113]. Healthcare costs and patient and family costs will be measured using a periodic retrospect health care consumption questionnaire designed by de Graaf et al. (2008) for use in the field of depression research [114]. This questionnaire is based on an existing cost diary [115] and retrospective cost questionnaires [116,117]. Containing 52 items, it measures the number and content of contacts with GPs, specialists, paramedics, alternative care, psychological care, hospital visits, medication, and self-help over a period of three months. To measure production losses we will use the patient modules (A-E) of the productivity and disease questionnaire (PRODISQ) [118].

\section{Quality of Life measures}

To measure the experiential impact of the disorder, the Work and Social Adjustment Scale (W\&SAS) [119] will be used. This 5 -item self-report scale examines to what extent the disorder impairs a person's everyday functioning. Items are rated on a 9 point Likert-scale, with higher scores indicating more severe impairment. Psychometric properties of the W\&SAS are found to be good $[119,120]$. Furthermore, to measure generic quality of life of the patients on the basis of societal appreciation of health condition, the EuroQol [121] will be used. To measure quality of life in terms of impairments due to physical and mental health status, we will use the RAND-36 [122]. This 36 item questionnaire measures physical and social functioning, role restriction due to physical or emotional problems, mental health, energy, pain, and general health perception. The RAND-36 has shown to be a reliable, valid and sensitive measure [122]. 


\section{Other measures \\ Working Alliance}

The past decades, it has become clear that therapeutic alliance is an essential element of the therapeutic process [123]. The stronger the collaborative and affective bond between patient and therapist, the larger the therapeutic change [124]. To measure this bond, the Working Alliance Inventory (WAI) $[69,125]$ will be used. The questionnaire consists of 36 items rated on a 5-point Likert scale and will be filled out by both patient and therapist. The internal consistency of this instrument was found to be high. As has been mentioned earlier, all therapy sessions will be videotaped. Therapeutic alliance will also be assessed by rating a random selection of videotapes using the Observer version of the Working Alliance Inventory-Short (WAI-O-S) [71,72].

\section{Genetics}

There is evidence that the same genetic factors that appear to moderate the efficacy of different classes of antidepressants are also involved in aspects of cognitive functioning [126]. The same polymorphisms are also associated with reactions on aversive stimuli [127-129]. Because changes in regulation of emotions and cognitive processes are core elements in therapeutic approaches such as CT and IPT, we expect that the efficacy of these therapies is influenced by genetic variations in polymorphisms. Therefore, we will obtain genetic material at baseline (buccal cotton swabs).

\section{Analyses}

Data-analysis will include intention-to-treat analyses, per-protocol analyses, change analyses and prognostic analyses. Analyses will include elementary head-to-head comparisons of the intervention groups as well as more complicated multivariate analyses (e.g., individual time series analysis, logistic regression analysis, multilevel analyses). Furthermore, in ancillary analysis, subgroups of the study sample according to symptom severity and DSM-IV classification will be examined for differential effects. In addition, we will determine the proportion of patients that show reliable and clinically significant improvement on the outcome measures. Our calculations will be based on the method of Jacobson and Truax [130] which prescribes that Clinical Improvement (CI) is based on both Reliable Change (RC), the extent to which the pre-to-post-difference score is reliable; and on Clinical Significant change (CSC), the extent to which post-treatment scores are clinically meaningful [131]. We will use chi-square tests to test the frequency differences in the $\mathrm{RC}, \mathrm{CSC}$, and CI between the three intervention groups.

Relapse (episode of MDD after remission) and recurrence (episode of MDD after recovery) in the course of follow-up (12 and 24 months) will be assessed using survival analysis (Cox proportional hazards regression).
Furthermore, using multi-level mediation models, we will investigate various potential treatment mediators (psychological processes responsible for therapeutic change) to identify mechanisms of change. We will use the revised and expanded McArthur guidelines with a central focus on the temporal aspect $[40,41]$. Furthermore, we will use structural equation modelling to test the relative strength of the factors involved (path analysis), an approach already successfully applied by Oei and colleagues [48].

\section{Discussion}

We presented the protocol of a study assessing the effectiveness, mechanisms of change and prevention of relapse/recurrence of CT and IPT for depression. While it is well known that both CT and IPT are effective treatments for depression, it is not entirely clear yet whether one therapy is superior to the other, especially in the long term. Furthermore, since response rates of both therapies are insufficient and the risk of relapse and recurrence is high, the challenge in contemporary depression research is the improvement of treatments to increase response rates and prevent relapse and recurrence. Studying the mechanisms of change in treatment might be a first step in improving every day clinical practice. Although in the past decades attention for mechanisms of change in psychotherapy has grown, this type of research is still in its infancy. It may be clear that there is a need for renewed methodologically wellconsidered research. With the current study, we hope to provide new insights in the issues stated above.

\section{Methodological Considerations}

The current study has several strengths, including randomisation of patients to three conditions (CT, IPT and a waiting list condition). The used design (RCT) is not only the standard for the evaluation of effectiveness of psychiatric treatments, but is also very valuable in studying mechanisms of therapeutic change $[132,133]$. Furthermore, we follow the recommendation of Kazdin to measure multiple potential mediators simultaneously and to include multiple follow-up measures at various time-points throughout a 2-year follow-up period. We assess both mediators and outcomes before and after therapy. This repeated measures design will provide a unique opportunity to evaluate whether change in cognitions occurs in advance of, and is related to, reduction in symptoms. In addition, to our knowledge, we are the first to compare CT with IPT head-to-head for relapse prevention and assess the underlying mechanisms of change using both explicit and implicit measures in a treatment study of depression to examine the level of therapeutic changes. To conclude, we will use state-of- 
the art statistical techniques to analyze temporality, causality and mechanisms of change.

However, the current study also has a number of limitations. In spite of the fact that we consider many potential mechanisms, there probably will be important (latent) processes that are not assessed in the current study. Even though we will use analysing techniques to prevent these biases as much as possible, there still is a chance that results will be contributed to the measured variables, whereas they are actually caused by other latent variables.

\section{Conclusions}

The current study will compare CT and IPT head-to-head in terms of effectiveness and the prevention of relapse. Furthermore, in order to investigate mechanisms of change, we will investigate potential mediators of CT for depression and test their specificity in comparison to IPT and vice versa. By including assessments on multiple time points in both the treatment- and follow-up phase, we try to investigate temporal relationships between change in potential mediators and outcome measures that are needed to identify causal pathways of therapeutic change. We will assess both specific and common treatment factors using both explicit and implicit measures. We hope to provide new insights in the mechanisms of change of CT and IPT for depression and through here contribute to the improvement of health care for adults suffering from depression.

\footnotetext{
Abbreviations

ASQ: Attributional Style Questionnaire; BDI-II: Beck Depression Inventory, second edition; BHS: Beck Hopelessness Scale; BSI: Brief Symptom Inventory; Cl: Clinical Improvement; CSC: Clinical Significant Change; CSPRS-6: Collaborative Study Psychotherapy Rating Scale - version 6; CT: Cognitive Therapy; DAS-A: Dysfunctional Attitude scale version a; DID: Diagnostic Inventory for Depression; DSM-IV: Diagnostic and Statistical Manual of Mental Disorders, fourth edition; IDS: Inventory of Depressive Symptomatology; IIP: Inventory of Interpersonal Problems; IPT: Interpersonal Therapy; LEIDS: Leiden Index of Depression Sensitivity; LIFE: Longitudinal Interval Follow-Up Evaluation; MDD: Major Depressive Disorder; PRODISO productivity and Disease questionnaire; QIDS: Quick Inventory of Depressive Symptoms; RC: Reliable Change; RCT: Radomised Controlled Trial; RIAGG: Regional Academic Community Mental Health Centre; RRS: Ruminative Response Scale; Sc-IAT: Single Category Implicit Association Test; SCID-I: Structural Clinical Interview for DSM-IV Axis I disorders; SCID-II: Structural Clinical Interview for DSM-IV Axis II disorders; SLSC-R: Self Liking and Self Competence Scale Revised; W\&SAS: Work and Social Adjustment Scale; WAl: Working Alliance Inventory; WAI-O-S: Observer rated version of the Working Alliance Inventory Short
}

\section{Acknowledgements and Funding}

We thank Annie Hendriks and Annie Raven for their assistance during the study. Furthermore, we thank Heleen van Teeseling for her earlier contributions to the study protocol. Rosanne Janssen has developed the infrastructure for the online data-collection. The study is funded by the research institute Experimental Psychopathology (EPP) and the academic RIAGG Maastricht.

\section{Author details}

'Department of Clinical Psychological Science, Faculty of Psychology and Neuroscience, Maastricht University, the Netherlands. ${ }^{2}$ Department of
Psychiatry and Neuropsychology, Maastricht University Medical Centre, Maastricht, the Netherlands. ${ }^{3}$ Vanderbilt University, Department of Psychology, Nashville, Tennessee, USA.

\section{Authors' contributions}

All authors, except for AR and LHJML, participated in the design of the study. MJHH obtained funding for the study. LHJML drafted the manuscript and carries out recruitment and data-collection. All authors contributed to the writing of the manuscript and have approved the final manuscript.

\section{Authors' information}

Lotte Lemmens (MSc) is a PhD Candidate at the department of Clinical Psychological Science at the faculty of Psychology and Neuroscience of Maastricht University. Arnoud Arntz (PhD) is a professor of Clinical and Experimental Psychopathology at Maastricht University. Frenk Peeters (MD, $\mathrm{PhD}$ ) is a psychiatrist at the Department of Psychiatry and Neuropsychology at Maastricht University Medical Centre. Steven Hollon (PhD) is a professor of Psychology at Vanderbilt University, with a cross-appointment in Psychiatry, whose research focuses on the nature and treatment of depression. Anne Roefs (PhD) is an assistant professor at Maastricht University. She is a cognitive psychologist, specialized in implicit measures. Marcus Huibers (PhD) is a professor of Empirically Directed Psychotherapy at Maastricht University. Next to scientific activities, AA, FPMLP and MJHH all work as clinicians at the Academic RIAGG Maastricht. The research group has ample experience in conducting both experimental research and clinical studies.

\section{Competing interests}

The authors declare that they have no competing interests.

Received: 29 April 2011 Accepted: 14 June 2011

Published: 14 June 2011

\section{References}

1. Mathers C, Fat DM, Boerma JT: The global burden of disease: 2004 update Geneva: World Health Organization; 2008.

2. Roelofs J, Muris P: Psychological treatments of depression. In Mood disorders: clinical management and research issues. Edited by: Griez EJL, Faravelli D, Nutt D, J, Zohar J. Chichester: John Wiley 2005:

3. Hollon SD, Ponniah $\mathrm{K}$ : A review of empirically supported psychological therapies for mood disorders in adults. Depression and Anxiety 2010, 27:891-932.

4. Beers MH, Fletscher AJ, Jones TV, Porter R, Berkwits M, Kaplan JL: Merck Manual Houten: Bohn Stafleu van Loghum; 2005.

5. Keller MB, Boland RJ: Implications of failing to achieve successful long term maintenance treatment of recurrent unipolar major depression. Biological Psychiatry 1998, 44:348-60.

6. Ormel J, Oldehinkel T, Brilman E, Brink Wv: Outcome of Depression and Anxiety in Primary Care: A Three-Wave 31/2-Year Study of Psychopathology and Disability. Arch Gen Psychiatry 1993, 50:759-66.

7. Van Londen L, Molenaar RPG, Goekoop JG, Zwinderman AH, Rooijmans HGM: Three- to 5-year prospective follow-up of outcome in major depression. Psychological Medicine 1998, 28:731-5.

8. Kazdin AE, Nock MK: Delineating mechanisms of change in child and adolescent therapy: methodological issues and research recommendations. Journal of Child Psychology and Psychiatry 2003, 44:1116-29.

9. Kraemer HC, Wilson GT, Fairburn CG, Agras WS: Mediators and Moderators of Treatment Effects in Randomized Clinical Trials. Archives of General Psychiatry 2002, 59:877-83.

10. Warmerdam L, van Straten A, Jongsma J, Twisk J, Cuijpers P: Online cognitive behavioral therapy and problem-solving therapy for depressive symptoms: Exploring mechanisms of change. Journal of Behavior Therapy and Experimental Psychiatry 2010, 41:64-70.

11. Beck AT, Rush AJ, SB F, Emery G: Cognitive therapy of depression New York: Guilford Press; 1979

12. Klerman GL, Weissman MM, Rounsaville BJ, Chevron ES: Interpersonal psychotherapy for depression New York: Basis Books; 1984

13. Cuijpers P, Geraedts AS, van Oppen P, Andersson G, Markowitz JC, van Straten A: Interpersonal Psychotherapy for Depression: A Meta-Analysis. American Journal of Psychiatry 2011, 168(6):581-92, Epub 2011 Mar 1. 
14. Cuijpers P, van Straten A, Andersson G, van Oppen P: Psychotherapy for depression in adults: A meta-analysis of comparative outcome studies. Journal of Consulting and Clinical Psychology 2008, 76:909-22.

15. Hollon SD, Thase ME, Markowitz JC: Treatment and prevention of depression. Psychological Science and Public Interest 2002, 3:39-77.

16. Beck AT, Rush AJ, Shaw BF, Emery G: Cognitive therapy of depression New York: Guilford Press; 1979

17. Butler AC, Chapman JE, Forman EM, Beck AT: The empirical status of cognitive-behavioral therapy: A review of meta-analyses. Clinical Psychology Review 2006, 26:17-31.

18. DeRubeis RJ, Crits-Christoph P: Empirically supported individual and group psychological treatments for adult mental disorders. Journal of Consulting and Clinical Psychology 1998, 66:37-52.

19. Emmelkamp PMG: Cognitieve gedragstherapeutische interventies bij depressie. In Directieve therapie 4. Edited by: Velden Kvd. Houten: Bohn Stafleu van Loghum; 1992:

20. Klerman GL, Weissman MM: New applications of interpersonal psychotherapy Washington, DC US: American Psychiatric Association; 1993

21. Strunk DR, DeRubeis RJ: Cognitive Therapy for Depression: A Review of Its Efficacy. Journal of Cognitive Psychotherapy 2001, 15:289-97.

22. Weissman MM: The efficacy of drugs and psychotherapy in the treatment of acute depressive episodes. The American Journal of Psychiatry 1979, 136:555-8.

23. Weissman MM, Markowitz JC: Interpersonal psychotherapy: Current status. Archives of General Psychiatry 1994, 51:599-606.

24. Elkin I, Shea MT, Watkins JT, Imber SD: National Institute of Mental Health Treatment of Depression Collaborative Research Program: General effectiveness of treatments. Archives of General Psychiatry 1989, 46:971-82.

25. Luty SE, Carter JD, McKenzie JM, Rae AM, Frampton CMA, Mulder RT, et al: Randomised controlled trial of interpersonal psychotherapy and cognitive-behavioural therapy for depression. British Journal of Psychiatry 2007, 190:496-502

26. McBride C, Atkinson L, Quilty LC, Bagby RM: Attachment as moderator of treatment outcome in major depression: A randomized control trial of interpersonal psychotherapy versus cognitive behavior therapy. Journal of Consulting and Clinical Psychology 2006, 74:1041-54.

27. Ablon JS, Jones EE: Psychotherapy process in the National Institute of Mental Health Treatment of Depression Collaborative Research Program. Journal of Consulting and Clinical Psychology 1999, 67:64-75.

28. Bockting CLH, Schene AH, Spinhoven P, Koeter MWJ, Wouters LF, Huyser J, et al: Preventing Relapse/Recurrence in Recurrent Depression With Cognitive Therapy: A Randomized Controlled Trial. Journal of Consulting and Clinical Psychology 2005, 73:647-57.

29. Fava GA, Ruini C, Rafanelli C, Finos L, Conti S, Grandi S: Six-Year Outcome of Cognitive Behavior Therapy for Prevention of Recurrent Depression. The American Journal of Psychiatry 2004, 161:1872-6.

30. Frank E, Kupfer DJ, Perel JM, Cornes C: Three-year outcomes for maintenance therapies in recurrent depression. Archives of General Psychiatry 1990, 47:1093-9.

31. Hollon SD: Does cognitive therapy have an enduring effect? Cognitive Therapy and Research 2003, 27:71-5.

32. Hollon SD, DeRubeis RJ, Shelton RC, Amsterdam JD, Salomon RM, O'Reardon JP, et al: Prevention of Relapse Following Cognitive Therapy vs Medications in Moderate to Severe Depression. Archives of General Psychiatry 2005, 62:417-22.

33. Paykel ES, Scott J, Cornwall PL, Abbott R, Crane C, Pope M, et al: Duration of relapse prevention after cognitive therapy in residual depression: Follow-up of controlled trial. Psychological Medicine: A Journal of Research in Psychiatry and the Allied Sciences 2005, 35:59-68.

34. Jarret RB, Kraft D, Doyle J, Foster BM, Eaves CG, Silver PC: Preventing recurrent depression using cognitive therapy with and without a continuation phase; a randomised clinical trial. Archives of General Psychiatry 2001, 58:381-8.

35. Teasdale JD, Segal ZV, Williams JM, Ridgeway VA, Soulsby JM, Lau MA: Prevention of relapse/recurrence in major depression by mindfulnessbased cognitive therapy. Journal of Consulting and Clinical Psychology 2000, 68:615-23.

36. Frank E, Kupfer DJ, Wagner EF, McEachran AB: Efficacy of interpersonal psychotherapy as a maintenance treatment of recurrent depression: Contributing factors. Archives of General Psychiatry 1991, 48:1053-9.
37. Frank E, Kupfer DJ, Buysse DJ, Swartz HA, Pilkonis PA, Houck PR, et al: Randomized trial of weekly, twice-monthly, and monthly interpersonal psychotherapy as maintenance treatment for women with recurrent depression. The American Journal of Psychiatry 2007, 164:761-7.

38. Garrat G, Ingram RE: Cognitive Processes in Cognitive Therapy: Evaluation of the Mechanisms of Change in the Treatment of Depression. Clinical Psychology 2007, 14:224-39.

39. Longmore RJ, Worrell M: Do we need to challenge thoughts in cognitive behavior therapy? Clinical Psychology Review 2007, 27:173-87.

40. Kazdin AE: Mediators and Mechanisms of Change in Psychotherapy Research. Annual Review of Clinical Psychology 2007, 3:1-27.

41. Kazdin AE: Understanding how and why psychotherapy leads to change. Psychotherapy Research 2009, 19:418-28.

42. DeRubeis RJ, Evans MD, Hollon SD, Garvey MJ, Grove WM, Tuason VB: How Does Cognitive Therapy Work? Cognitive Change and Symptom Change in Cogntive Therapy and Pharmacotherapy for Depression. Journal of Consulting and Clinical Psychology 1990, 58:862-9.

43. Furlong M, Oei TPS: Changes to automatic thoughts and dysfuntional attitudes in group CBT for depression. Behavioural and Cognitive Psychotherapy 2002, 30:351-60.

44. Kwon S, Oei TPS: Cognitive change processes in a group cognitive behavior therapy of depression. Journal of Behavior Therapy and Experimental Psychiatry 2003, 34:73-85.

45. Quilty LC, MCBride C, Bagby RM: Evidence for the cognitive mediational model of cognitive behavioural therapy for depression. Psychological Medicine 2008, 38:1531-41.

46. Coleman D, Cole D, Wuest L: Cognitive and Psychodynamic Mechanisms of Change in Treated and Untreated Depression. Journal of Clinical Psychology 2010, 66:215-28.

47. Kolko DJ, Brent DA, Baugher M, Bridge J, Birmaher B: Cognitive and family therapies for adolescent depression: Treatment specificity, mediation, and moderation. Journal of Consulting and Clinical Psychology 2000, 68:603-14.

48. Oei TPS, Bullbeck K, Campbell JM: Cognitive change process during group cognitive behaviour therapy for depression. Journal of Affective Disorders 2006, 92:231-41.

49. Oei TPS, Shuttlewood GJ: Specific and Nonspecific factors in psychotherapy; a case of cognitive therapy for depression. Clinical Psychology Review 1996, 16:83-103.

50. Nisbett RE, Wilson TD: Telling more than we can know: Verbal reports on mental processes. Psychological Review 1977, 84:231-59.

51. De Houwer J, Teige-Mocigemba S, Spruyt A, Moors A: Implicit measures: A normative analysis and review. Psychological Bulletin 2009, 135:347-68.

52. Roefs A, Huijding J, Smulders FTY, MacLeod CM, de Jong PJ, Wiers RW, et al: Implicit measures of association in psychopathology research. Psychological Bulletin 2011, 137:149-93.

53. Kraemer HC, Stice E, Kazdin AE, Offord D, Kupfer DJ: How Do Risk Factors Work Together? Mediators, Moderators, and Independent, Overlapping and Proxy Risk Factors. American Journal of Psychiatry 2001, 158:848-83.

54. Baron RM, Kenny DA: The moderatorâ€"mediator variable distinction in social psychological research: Conceptual, strategic, and statistical considerations. Journal of Personality and Social Psychology 1986, 51:1173-82.

55. Murphy R, Cooper Z, HS D, Fairburn CG: How do psychological treatments work? Investigating mediators of change. Behavioural Research Therapy 2009, 47:1-5.

56. Dorrepaal E, van Nieuwenhuizen C, Schene A, de Haan R: De effectiviteit van cognitieve en interpersoonlijke therapie bij depressiebehandeling: een meta-analyse. Tijdschrift voor Psychiatrie 1998, 40:27-39.

57. Willemse Y, Trijsburg RW: Cognitieve gedragstherapie en interpersoonlijke psychotherapie. Een analyse van kritische succesfactoren. Tijdschrift voor Psychiatrie 2005, 47:593-602.

58. Hollon SD, Jarrett RB, Nierenberg AA, Thase ME, Trivedi M, Rush AJ: Psychotherapy and Medication in the Treatment of Adult and Geriatric Depression: Which Monotherapy or Combined Treatment? Journal of Clinical Psychiatry 2005, 66:455-68.

59. First MB, Spitzer RL, Gibbon M, Williams JBW: Structured Clinical Interview for DSM-IV Axis I Disorders (SCID-I) New York: Biometrics Research Department, New York State Psychiatric Institute; 1995.

60. Dobson KS: A meta-analysis of the efficacy of cognitive therapy for depression. Journal of Consulting and Clinical Psychology 1989, 57:414-9. 
61. Gloaguen Vr, Cottraux J, Cucherat M, Blackburn I-M: A meta-analysis of the effects of cognitive therapy in depressed patients. Journal of Affective Disorders 1998, 49:59-72.

62. Parker G, Parker I, Brotchie H, Stuart S: Interpersonal psychotherapy for depression? The need to define its ecological niche. Journal of Affective Disorders 2006, 95:1-11.

63. Robinson LA, Berman JS, Neimeyer RA: Psychotherapy for the treatment of depression: A comprehensive review of controlled outcome research. Psychological Bulletin 1990, 108:30-49.

64. First MB, Gibbon M, Spitzer RL, Williams JBW, Benjamin LS: Structured Clinical Interview for DSM-IV Axis II Personality Disorders (SCID-II) Washington, D.C: American Psychiatric Press; 1997.

65. Klein DF: NIMH collaborative research on treatment of depression. Archives of General Psychiatry 1990, 47:682-4.

66. Keller MB, Lavori PW, Friedman B, Nielsen E, Endicott J, McDonald-Scott P, et al: The Longitudinal Interval Follow-up Evaluation: A Comprehensive Method for Assessing Outcome in Prospective Longitudinal Studies. Archives of General Psychiatry 1987, 44:540-8.

67. Hill CE, O'Grady KE, Elkin I: Applying the Collaborative Study Psychotherapy Rating Scale to rate therapist adherence in cognitivebehavior therapy, interpersonal therapy, and clinical management. Journal of Consulting and Clinical Psychology 1992, 60:73-9.

68. Hatcher RL, Barends AW: How a return to theory could help alliance research. Psychotherapy: Theory/Research/Practice/Training 2006, 43:292-9.

69. Horvath AO, Greenberg LS: Development and validation of the Working Alliance Inventory. Journal of Counseling Psychology 1989, 36:223-33.

70. Osbourne CA: The Role of Alliance and Symptomatic Change Within Cognitive Behaviour Therapy for Depression Albany: Massey University; 2010.

71. Tichenor V, Hill CE: A comparison of six measures of working alliance. Psychotherapy: Theory, Research, Practice, Training 1989, 26:195-9.

72. Tracey TJ, Kokotovic AM: Factor structure of the Working Alliance Inventory. Psychological Assessment: A Journal of Consulting and Clinical Psychology 1989, 1:207-10.

73. Beck AT, Steer R, Brown GK: Beck Depression Inventory II: Manual Boston: Hartcourt Brace; 1996.

74. Does van der W: BDI-II-NL: Handleiding: De Nederlandse versie van de Beck Depressie Inventory. 2 edition. Enschede: Ipskamp; 2002.

75. Whisman M, Perez J, Ramel W: Factor structure of the Beck Depression Inventory-Second Edition (BDI-II) in a student sample. Journal of Clinical Psychology 2000, 56:545-51.

76. Rush AJ, Trivedi MH, Ibrahim HM, Carmody TJ, Arnow B, Klein DN, et al: The 16-item Quick Inventory of Depressive Symptomatology (QIDS), clinician rating (QIDS-C), and self-report (QIDS-SR): A psychometric evaluation in patients with chronic major depression. Biological Psychiatry 2003, 54:573-83

77. Rush AJ, Carmody T, Reimitz PE: The Inventory of Depressive Symptomatology (IDS): clinician (IDS-C) and Self-Report (IDS-SR) ratings of depressive symptoms. International Journal of Methods in Psychiatric Research 2000, 9:45-59.

78. Trivedi MH, Rush AJ, Ibrahim HM, Carmody TJ, Biggs MM, Suppes T, et al: The Inventory of Depressive Symptomatology, Clinician Rating (IDS-C) and Self-Report (IDS-SR), and the Quick Inventory of Depressive Symptomatology, Clinician Rating (QIDS-C) and Self-Report (QIDS-SR) in public sector patients with mood disorders: A psychometric evaluation. Psychological Medicine: A Journal of Research in Psychiatry and the Allied Sciences 2004, 34:73-82

79. Derogatis LR, Melisaratos N: The Brief Symptom Inventory: An introductory report. Psychological Medicine: A Journal of Research in Psychiatry and the Allied Sciences 1983, 13:595-605.

80. Beurs de E, Zitman F: De Brief Symptom Inventory (BSI). De betrouwbaarheid en validiteit van een handzaam alternatief voor de SCL-90 Leiden: Leids Universitair Medisch Centrum; 2005.

81. Galdón M, Durá E, Ferrando M, Murgui S, Pérez S, Ibañez E: Psychometric properties of the Brief Symptom Inventory-18 in a Spanish breast cancer sample. Journal of Psychometric Research 2008, 65:533-9.

82. Graaf de LE, Huibers MJH: Introductie van de Diagnostic Inventory for Depression in Nederland. Tijdschrift voor Psychiatrie 2009, 51:675-86.

83. Zimmerman M, Sheeran T, Young D: The Diagnostic Inventory for Depression: a self-report scale to diagnose DSM-IV major depressive disorder. Clinical Psychology 2004, 60:87-110.
84. Warshaw MG, Dyck I, Allsworth J, Stout RL, Keller MB: Maintaining reliability in a long-term psychiatric study: an ongoing inter-rater reliability monitoring program using the longitudinal interval follow-up evaluation. Journal of Psychiatric Research 2001, 35:297-305.

85. Warshaw MG, Keller MB, Stout RL: Reliability and Validity of the Longitudinal interval follow-up evaluation for assessing outcome of anxiety disorders. Journal of Psychiatric Research 1994, 28:531-45.

86. Graaf de LE, Roelofs J, Huibers MJH: Measuring dysfunctional attitudes in the general population: the DAS-A revised. Cognitive therapy and research 2009, 33:345-55

87. Weissman AN, Beck AT: Development and validation of the Dysfunctional Attitude Scale; paper presented at the annual meeting of the Association for the Advancement of Behavior Therapy. 1978.

88. Weissmann AN, Beck AT: Development and validation of the Dysfunctional Attitude Scale; a prelimary investigation Toronto: O. N.; 1978.

89. Beck AT, Brown GK, Steer RA, Weissmann AN: Factor Analysis of the Dysfunctional Attitude Scale in a Clinical Population. Journal of Consulting and Clinical Psychology 1991, 3:478-83.

90. Nelson LD, Stern SL, Cicchetti DV: The Dysfunctional attitude scale, how well can it measure depressive thinking? journal of Psychopathology and behavioural assessment 1992, 4:217-23.

91. Oliver M, Baumgart EP: The dysfunctional attitude scale: psychometric properties and relation to depression in an unselected adult population. Cognitive therapy and research 1985, 9:161-7.

92. Power MJ, Katz R, McGuffin P, Duggan CF, Lam D, Beck AT: The Dysfunctional Attitude Scale (DAS): A Comparison of Forms A and B and Proposals for a New Subscaled Version. Journal of Research in Personality 1994, 28:263-76.

93. Cohen L, Bout van den J, Kramer W, Vliet van T: A Dutch Attributional Style Questionnaire: Psychometric Properties and Findings of Some Dutch-American Differences. Cognitive therapy and research 1986, 10:665-9.

94. Peterson C, Semmel A, Baeyer von C, Abramson LY, Metalsky Gl, Seligman MEP: The attributional style questionnaire. Cognitive therapy and research 1982, 6:287-300.

95. Molen van der HT, Perreijn S, Hout van den MA: Klinische psychologie: theorieën en psychopathologie Groningen: Wolters-Noordhoff; 1997.

96. Karpinski A, Steinman RB: The Single Category Implicit Association Test as a measure of Implicit Social Cognition. Journal of Personality and Social Psychology 2006, 91:16-32.

97. Greenwald AG, Nosek BA, Banaji MR: 'Understanding and using the Implicit Association Test: I. An improved scoring algorithm': Correction to Greenwald et al. (2003). Journal of Personality and Social Psychology 2003, 85.

98. Bosson JK, Swann WB Jr, Pennebaker JW: Stalking the perfect measure of implicit self-esteem: The blind men and the elephant revisited? Journal of Personality and Social Psychology 2000, 79:631-43.

99. Glashouwer KA, de Jong PJ: Impliciete persoonlijkheidstrekken en psychopathologie: Achtergrond, huidige inzichten en perspectieven. Gedragstherapie 2008, 41:121-34

100. Nosek BA, Greenwald AG, Banaji MR: Understanding and Using the Implicit Association Test: II. Method Variables and Construct Validity. Personality and Social Psychology Bulletin 2005, 31:166-80.

101. Olson MA, Fazio RH: Relations between implicit measures of prejudice: What are we measuring? Psychological Science 2003, 14:636-9.

102. Beck AT, Weissman A, Lester D, Trexler L: The measurement of pessimism: The Hopelessness Scale. Journal of Consulting and Clinical Psychology 1974, 42:861-5.

103. Beck AT, Steer RA: Manual for the Beck Hopelessness Scale San Antonio, TX: Psychological Corporation; 1988.

104. Dyce JA: Factor structure of the Beck Hopelessness Scale. Journal of Clinical Psychology 1996, 52:555-8.

105. Young MA, Halper IS, Clark DC, Scheftner WA: An item-response theory evaluation of the Beck Hopelessness Scale. Cognitive Therapy and Research 1992, 16:579-87.

106. Horowitz LM, Rosenberg SE, Baer BA, Ureño G, Villaseñor VS: Inventory of Interpersonal problems: Psychometric properties and clinical applications. Journal of Consulting and Clinical Psychology 1988, 56:885-92.

107. Beurs de DP: Further validation of the Leiden Index of Depression Sensitivity. Tijdschrift voor Psychiatrie; samenvattingen 37ste voorjaarscongres 2009, supplement 1. 
108. Does van der W: Cognitive reactivity to sad mood: structure and validity of a new measure. Behaviour Research and Therapy 2002, 40:105-20

109. Nolen-Hoeksema S, Morrow J: A prospective study of depression and posttraumatic stress symptoms after a natural disaster: The 1989 Loma Prieta earthquake. Journal of Personality and Social Psychology 1991, 61:115-21.

110. Raes F, Hermans D, Eelen P: Kort instrumenteel De Nederlandstalige versie van de Ruminative Response Scale (RRS-NL) en de Rumination on Sadness Scale (RSS-NL). Gedragstherapie 2003, 36:97-104

111. Tafarodi RW, Swann WB: Two-dimensional self-esteem: Theory and measurement. Personality and Individual Differences 2001, 31:653-73.

112. Vandromme H, Hermans D, Spruyt A, Eelen P: Dutch translation of the Self-Liking/Self-Competence Scale - Revised: A confirmatory factor analysis of the two-factor structure. Personality and Individual Differences 2007, 42:157-67.

113. Drummond MF, Schulpher MJ, Torrance GW, O'Brien B, Stoddart GL: Methods for the Economic Evaluation of Health Care Programmes Oxford: Oxfor University Press; 2005.

114. Graaf de LE, Gerhards S, Evers S, Arntz A, Riper H, Severens J, et al: Clinical and cost-effectiveness of computerised cognitive behavioural therapy for depression in primary care: Design of a randomised trial. BMC Public Health 2008, 8:224.

115. Goossens MEJB, Rutten-van Mölken MPMH, Vlaeyen JWS, van der Linden SMJP: The cost diary: a method to measure direct and indirect costs in cost-effectiveness research. Journal of Clinical Epidemiology 2000 53:688-95.

116. Hakkaart-van Roijen L: Trimbos/iMTA questionnaire for Costs associated with Psychiatric Illness (TiC-P) Rotterdam: Institute for medical Technology Assessment, Erasmus University; 2002.

117. van Asselt ADI, Dirksen CD, Arntz A, Giesen-Bloo JH, van Dyck R, Spinhoven $P$, et al: Out-patient psychotherapy for borderline personality disorder: Cost-effectiveness of schema-focused therapy v. transferencefocused psychotherapy. British Journal of Psychiatry 2008, 192:450-7.

118. Koopmanschap M, Meerding W, Evers S, Severens J, Burdorf A, Brouwer W: Handleiding voor het gebruik van PRODISQ. Een modulaire vragenlijst over de relatie tussen ziekte en productiviteitskosten. Toepasbaar bij economische evaluaties van gezondheidszorgprogramma's voor patiënten en werknemers Rotterdam/Maastricht: Erasmus Universiteit Rotterdam/Erasmus Medisch Centrum/Universiteit Maastricht; 2004.

119. Mundt JC, Marks IM, Greist JH, Shear K: The Work and Social Adjustment Scale: A simple accurate measure of impairment in functioning. British Journal of Psychiatry 2002, 180:461-4.

120. Mataix-Cols D, Cowley AJ, Hankins M, Schneider A, Bachofen M Kenwright $M$, et al: Reliability and validity of the Work and Social Adjustment Scale in phobic disorders. Comprehensive Psychiatry 2005, 46:223-8.

121. EuroQolGroup: EuroQol - a new facility for the measurement of healthrelated quality of life. Health Policy 1990, 16:199-208.

122. van der Zee Kl, Sanderman R: Het meten van de algemene gezondheidstoestand met de RAND-36: een handleiding Groningen: Noordelijk Centrum voor Gezondheidsvraagstukken; 1993.

123. Martin DJ, Garske JP, Davis MK: Relation of the therapeutic alliance with outcome and other variables: a meta-analytic review. Journal of Consulting and Clinical Psychology 2000, 68:438-50.

124. Horvath AO, Bedi RP: The alliance. In Psychotherapy relationships that work: Therapist contributions and responsiveness to patients. Edited by: Norcross JC. New York: Oxford University Press; 2002:37-69.

125. Vervaeke GAC, Vertommen H: De Werkalliantievragenlijst (wav). Gedragstherapie 1996, 2:139-44.

126. Goldberg TE, Weinberger DR: Genes and the parsing of cognitive processes. Trends in Cognitive Sciences 2004, 8:325-35.

127. Domschke K, Braun M, Ohrmann P, Suslow T, Kugel H, Bauer J, et al: Association of the functional -1019C/G 5-HT[sub]1A[/sub] polymorphism with prefrontal cortex and amygdala activation measured with $3 \mathrm{~T} \mathrm{fMRI}$ in panic disorder. International Journal of Neuropsychopharmacology 2006, 9:349-55.

128. Pezawas L, Meyer-Lindenberg A, Drabant EM, Verchinski BA, Munoz KE, Kolachana BS, et al: 5-HTTLPR polymorphism impacts human cingulateamygdala interactions: A genetic susceptibility mechanism for depression. Nature Neuroscience 2005, 8:828-34.
129. Smolka MN, Schumann G, Wrase J, Grusser SM, Flor H, Mann K: Catechol-OMethyltransferase val158met Genotype Affects Processing of Emotional Stimuli in the Amygdala and Prefrontal Cortex. Journal of Neuroscience 2005, 25:145-59.

130. Jacobson NS, Truax P, Kazdin AE: Clinical significance: A statistical approach to defining meaningful change in psychotherapy research. Methodological issues \& strategies in clinical research Washington, DC US: American Psychological Association; 1992, 631-48.

131. Evans C, Margison R, Barkham M: The contribution of reliable and clinically significant change methods to evidence-based mental health. Evidence-Based Mental health 1998, 1:70-2.

132. Nock MK: Conceptual and design essentials for evaluating mechanisms of change. Alcoholism: Clinical and Experimental Research 2007, 31:4S-12S.

133. Haaga DAF, Stiles WB: Randomized clinical trials in psychotherapy research:Methodology, design, and evaluation. In Handbook of psychological change: Psychotherapy processes and practices for the 21st Century. Edited by: Snyder CR, Ingram RE. New York: Wiley; 2000:14-39.

doi:10.1186/1745-6215-12-150

Cite this article as: Lemmens et al: Effectiveness, relapse prevention and mechanisms of change of cognitive therapy vs. interpersonal therapy for depression: Study protocol for a randomised controlled trial. Trials 2011 12:150.

\section{Submit your next manuscript to BioMed Central and take full advantage of:}

- Convenient online submission

- Thorough peer review

- No space constraints or color figure charges

- Immediate publication on acceptance

- Inclusion in PubMed, CAS, Scopus and Google Scholar

- Research which is freely available for redistribution

Submit your manuscript at www.biomedcentral.com/submit
C Biomed Central 